\title{
Steric Control in Reactions of N-Heterocyclic Phosphorus \\ Electrophiles with Pentacarbonyl Manganate(-I)
}

\section{Papendick, Marius}

2018-09-17

Papendick , M , Feil , C M , Nieger , M \& Gudat , D 2018 , ' Steric Control in Reactions of N-Heterocyclic Phosphorus Electrophiles with Pentacarbonyl Manganate(-I) ' , Zeitschrift für anorganische und allgemeine Chemie , vol. 644 , no. 17 , pp. 1006-1010 . https://doi.org/10.1002/zaac.201800178

http://hdl.handle.net/10138/324821

https://doi.org/10.1002/zaac.201800178

unspecified

acceptedVersion

Downloaded from Helda, University of Helsinki institutional repository.

This is an electronic reprint of the original article.

This reprint may differ from the original in pagination and typographic detail.

Please cite the original version. 


\title{
Steric control in reactions of $\mathrm{N}$-heterocyclic phosphorus electrophiles with pentacarbonyl manganate(-I)
}

\author{
Marius Papendick, ${ }^{[a]}$ Christoph M. Feil, ${ }^{[a]}$ Martin Nieger ${ }^{[b]}$ and Dietrich Gudat ${ }^{\star[a]}$
}

Dedicated to Professor A. C. Filippou on the occasion of his $60^{\text {th }}$ birthday.

\begin{abstract}
Metathesis of $\mathrm{Na}\left[\mathrm{Mn}(\mathrm{CO})_{5}\right]$ with $\mathrm{N}$-tBu and $\mathrm{N}$-Mes substituted, electrophilic $\mathrm{N}$-heterocyclic phosphane derivatives afforded in the first case an ionic N-heterocyclic phosphenium (NHP) metalate and in the second case a covalent phosphenium complex. The products were characterized by analytical and spectral data and the NHP complex as well by a single-crystal X-ray diffraction study. A DFT study allows relating the different outcome of the reactions studied with the energetics of the decarbonylation of the appropriate NHP metalates. Closer evaluation reveals steric factors as the key to explaining the observed behavior, and indicates that their impact displays close parallels to $\mathrm{NHC}$ chemistry.
\end{abstract}

\section{Introduction}

Neutral phosphenium complexes $\mathrm{R}_{2} \mathrm{P}=\left[\mathrm{ML}_{n}\right]^{[1]}$ featuring a metalligand bond with formal double bond character are well-known for a range of different transition metals, ${ }^{[2]}$ but appropriate manganese derivatives have remained rare. ${ }^{[3]}$ Following an earlier report on the synthesis of the cobalt complexes 1 (Scheme 1) with $\mathrm{N}$-heterocyclic phosphenium (NHP) ligands, ${ }^{[4]}$ we recently described a manganese complex $2 \mathrm{c}$ that was found to exhibit unique chemical reactivity. ${ }^{[6]}$ In extension of the known ability of neutral phosphenium complexes to undergo reversible addition reactions with protic substrates $(\mathrm{HX}),{ }^{[5]}$ complex $2 \mathrm{c}$ allows for the hydrogenation and alkylation of the $\mathrm{Mn}-\mathrm{P}$ double bond by stepwise attachment of $\mathrm{H}^{-} / \mathrm{H}^{+}$or $\mathrm{CH}_{3}-/ \mathrm{H}^{+}$pairs and subsequent photochemical fission of $\mathrm{H}_{2}$ or $\mathrm{CH}_{4}$, respectively. ${ }^{[6][7]}$ Moreover, 2c can act as active catalyst enabling the dehydrogenation of ammonia borane under mild conditions, ${ }^{[6]}$ and treatment with BuLi or $\mathrm{Pr}_{2} \mathrm{NLi}$ resulted in $\mathrm{CH}$-deprotonation in 4-position of the $\mathrm{N}$-heterocycle. This reaction was unprecedented for NHPs and resulted in the synthesis of an isolable phosphorus-analogue of an "abnormal" (or meso-ionic) carbene. ${ }^{[7]}$

[a] MSc Marius Papendick, MSc. Christoph M. Feil, Prof. Dr. Dr. h.c. Dietrich Gudat,

Institute for Inorganic Chemistry

University of Stuttgart

Pfaffenwaldring 55, Stuttgart, Germany

E-mail: Gudat@iac.uni-stuttgart.de

[b] Dr. Martin Nieger

Dept. of Chemistry,

University of Helsinki,

P.O Box 55, 00014 University of Helsinki, Finland

Supporting information for this article is given via a link at the end of the document

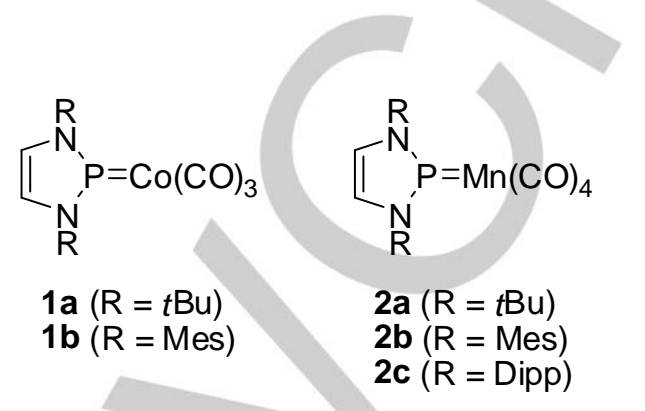

Scheme 1. Molecular structures of $\mathrm{N}$-heterocyclic phosphenium (NHP) complexes (Mes = 2,4,6-Me ${ }_{3} \mathrm{C}_{6} \mathrm{H}_{2}$; Dipp = 2,6-i $\mathrm{Pr}_{2} \mathrm{C}_{6} \mathrm{H}_{3}$ ).

Hypothesizing that the diverse regioselectivity revealed in the reactions of 2c with nucleophiles and bases (hydride attack at the phosphorus atom vs. $\mathrm{CH}$-deprotonation with lithium alkyls and amides) might be controlled by steric constraints, ${ }^{[7]}$ we became interested in accessing analogues of $2 c$ featuring $\mathrm{N}$ substituents of different steric bulk. In view of the successful synthesis of the cobalt complexes $1,{ }^{[4]}$ complexes with N-Mes (2b) and $\mathrm{N}$-tBu-substituents (2a) were considered as viable targets that should like $\mathbf{2 c}$ be readily accessible from reactions of appropriate electrophilic NHP-precursors with pentacarbonyl manganate(-I). We report here that the outcome of these reactions depends subtly on intricate steric interactions between the reactants, and provide an explanation for the observed effects based on computational studies.

\section{Results and Discussion}

The reaction of equimolar amounts of $\mathrm{Na}\left[\mathrm{Mn}(\mathrm{CO})_{5}\right]$ and 2bromo-diazaphospholene $\mathbf{3 b}$ proceeded as expected by salt metathesis to yield the desired phosphenium complex $\mathbf{2 b}$ (Scheme 2). The product was isolated in the form of analytically pure, orange crystals after work-up of the reaction mixture and fully characterized. The ${ }^{31} \mathrm{P}\left\{{ }^{1} \mathrm{H}\right\}$ NMR spectrum displays a broad singlet with a chemical shift of $240 \mathrm{ppm}$ which is comparable to that of $2 \mathrm{c}^{[6]}$ and falls into the typical range of phosphenium complexes of this type. The intense signal broadening is, as in 2c, caused by partially collapsed spin coupling with the adjacent quadrupolar ${ }^{55} \mathrm{Mn}$ nucleus $(I=5 / 2,100 \%$ natural abundance). The vCO modes in the IR-spectrum of $\mathbf{2 b}(\tilde{v}=2026,1948,1918$ $\mathrm{cm}^{-1}$ in THF) are likewise nearly identical to those of $2 \mathrm{c}(\tilde{v}=$ 2019, 1937, $1903 \mathrm{~cm}^{-1}\left[{ }^{[6]}\right)$, and their position reflects the strong $\pi$-acceptor character of the NHP-ligand. 


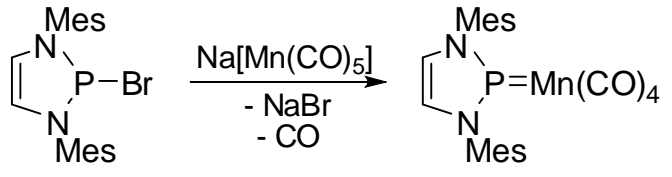

$3 b$

$2 b$

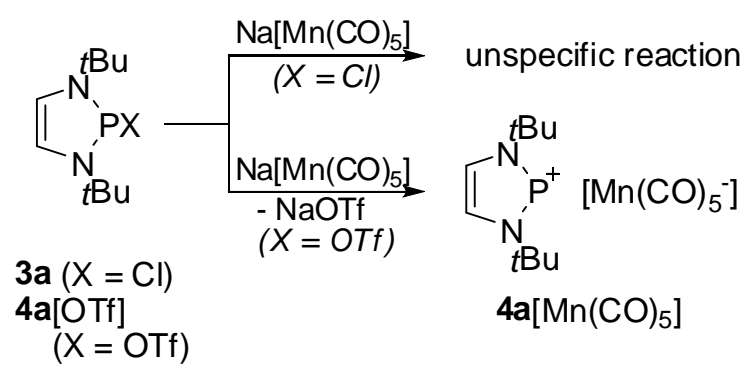

Scheme 2. Reactions of $\mathrm{N}$-heterocyclic phosphane derivatives with $\mathrm{Na}\left[\mathrm{Mn}(\mathrm{CO})_{5}\right]\left(\mathrm{Mes}=2,4,6-\mathrm{Me}_{3} \mathrm{C}_{6} \mathrm{H}_{2} ; \mathrm{OTf}=\mathrm{CF}_{3} \mathrm{SO}_{3}\right)$.

The single-crystal X-ray diffraction study of $\mathbf{2 b}$ reveals the presence of isolated molecules (Figure 1) featuring the planar coordination geometry at the phosphorous atom (sum of bond angles $\left.359.96(11)^{\circ}\right)$ and very short P-Mn distance (P1-Mn1 2.0631(3) $\AA$, cf. P-Mn 2.0625(11) $\AA$ for 2c ${ }^{[6]}$ ) which are typical characteristics of a species with a formal $\mathrm{P}-\mathrm{Mn}$ double bond. ${ }^{[2]}$ The close analogy between $\mathbf{2 b}$ and its congener $\mathbf{2 c}$ is further emphasized by the fact that, like the $\mathrm{Mn}-\mathrm{P}$ distance, the other metrical parameters in the NHP-Mn(CO $)_{4}$ fragments of both compounds are generally also indistinguishable within experimental error. A single exception is the orientation of the $\mathrm{NHP}$ ring plane in relation to the metal coordination polyhedron which is in $\mathbf{2 c}$ essentially orthogonal to the equatorial plane of the $\mathrm{Mn}$-centred trigonal bipyramid and adopts in $\mathbf{2 b}$ a tilted alignment (twist angle $12.3(2)^{\circ}$ ). DFT-calculations (at the RIPBE-D3BJ/def2-tzvp level, see experimental section for details) on a model complex $\mathbf{2} \mathbf{b}^{\prime}$ featuring $\mathrm{N}-2,6-x y l y l$ instead of $\mathrm{N}$ mesityl substituents suggest that the orthogonal orientation observed for $\mathbf{2 c}$ should also be energetically favored for $\mathbf{2 b}$. However, the calculations predict as well that rotation of the NHP-ligand around the Mn-P bond is feasible at nearly negligible energetic cost (the energy of the corresponding vibrational mode was calculated as $3 \mathrm{~cm}^{-1}$ ), and we interpret the twisted orientation observed for crystalline $\mathbf{2} \mathbf{b}$ thus as a consequence of crystal packing effects.

Reactions of $\mathrm{Na}\left[\mathrm{Mn}(\mathrm{CO})_{5}\right]$ with the $\mathrm{N}$-tBu-substituted 2-chlorodiazaphospholene 3a (Scheme 2) produced mixtures which displayed a broad ${ }^{31} \mathrm{P}$ NMR signal in the region between 180 and $200 \mathrm{ppm}$. The position and linewidth of this signal varied between different experiments, and work-up of the mixtures failed to produce any well-defined products. The observed spectral characteristics are typical for solutions containing dynamically equilibrating mixtures of diazaphospholenium ions and halogeno-diazaphospholenes [8] and suggest that the intended reaction remained incomplete, yielding only blends of metathesis products and unreacted starting materials.

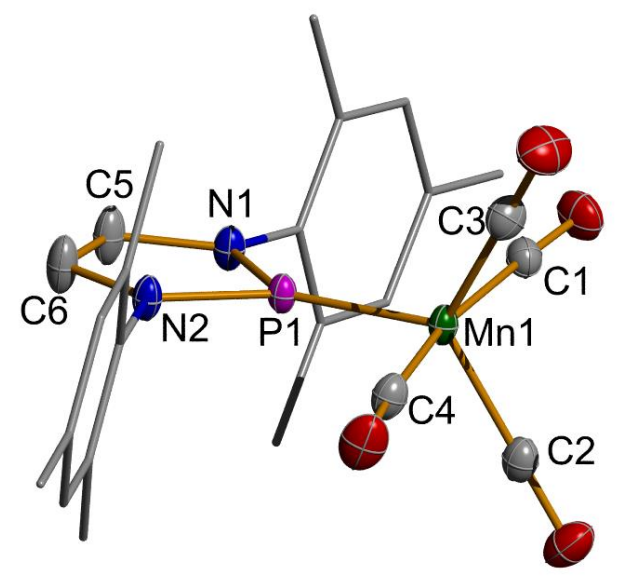

Figure 1. Molecular structure of $\mathbf{2} \mathbf{b}$ in the crystal. Thermal ellipsoids are drawn at the $50 \%$ probability level. Hydrogen atoms are omitted and the N-Mes substituents shown as a wireframe model for clarity. Selected bond lengths $[\AA]$ and angles $\left[{ }^{\circ}\right]$ : Mn1-C1 1.8383(12), Mn1-C2 1.8269(12), Mn1-C3 1.8209(13), Mn1-C4 1.8384(12), Mn1-P1 2.0631(3), P1-N1 1.6751(9), P1-N2 1.6792(9), N(1)-C(5) 1.3993(14), N2-C6 1.3991(14), C5-C6 1.3443(16); N1P1-N2 89.60(5), N1-P1-Mn1 136.48(3), N(2)-P(1)-Mn(1) 133.87(3).

More consistent results were obtained when the $\mathrm{N}$-tBusubstituted diazaphospholenium triflate $4 \mathrm{a}[\mathrm{OTf}]$ was employed as starting material. Work-up of the reaction afforded in this case a dark red, slightly viscid solid. The ${ }^{31} \mathrm{P}$ NMR spectrum of this product displayed a signal with a reproducible chemical shift of $201 \mathrm{ppm}$ which matches that of the starting material and suggests formulating the product as ionic diazaphospholenium salt. This assignment is further confirmed by the observation of a strongly deshielded ${ }^{1} \mathrm{H}$ NMR signal at $8.4 \mathrm{ppm}$ for the protons in 4,5-positions of the heterocyclic ring. An IR spectrum of the isolated product gave rise to a pattern of $v$ CO modes $(\tilde{v}=2011$, 1896, $1846 \mathrm{~cm}^{-1}$ ) that differ from those of $\mathbf{2 b}$ but are in reasonable agreement with the data derived from DFT calculations on a contact ion pair $4 \mathrm{a}\left[\mathrm{Mn}(\mathrm{CO})_{5}\right] \quad(\tilde{v}=2000,1899$, $1873 \mathrm{~cm}^{-1}$, see supporting information). Finally, this suggested composition was also confirmed by an elemental analysis.

Initial formation of a diazaphospholenium carbonylmetalate rather than a covalent complex had previously been observed during the reaction of $3 \mathbf{a}$ with a tetracarbonyl cobaltate (Scheme 3). ${ }^{[4]}$ However, while $4 \mathrm{a}\left[\mathrm{Co}(\mathrm{CO})_{4}\right]$ decarbonylates smoothly at ambient temperature to yield phosphenium complex $1 \mathrm{a}$ as final product, ${ }^{[4]}$ the analogous conversion of $4 \mathrm{a}\left[\mathrm{Mn}(\mathrm{CO})_{5}\right]$ remained unobservable even under forcing conditions. Prolonged reflux in toluene, heating in a microwave reactor, or irradiation with UVlight caused only unspecific decomposition but did not afford measurable amounts of the desired $\mathrm{N}$-tBu-substituted analogue of $\mathbf{2 b}, \mathbf{c}$. We attribute this inert behavior of $\mathbf{4 a}\left[\mathrm{Mn}(\mathrm{CO})_{5}\right]$ to an increased steric demand of both molecular fragments arising from the presence of an extra carbonyl ligand (as compared to $\left.\left[\mathrm{Co}(\mathrm{CO})_{4}\right]^{-}\right)$in the anion and the bulky $t$ Bu-substituents in the cation. In the same way as in complexes of $\mathrm{N}$-heterocyclic carbenes (NHCs), ${ }^{[9]}$ the combination of both factors is thought to amplify repulsive interactions between both fragments which 
may in turn obstruct a close approach of the phosphorus and manganese atoms required for bond formation. Since the repulsive interactions can affect the energies of both the transition state and the final complex formed, the inhibition of phosphenium complex formation can in principle be due to kinetic or thermodynamic effects, or a combination of both.

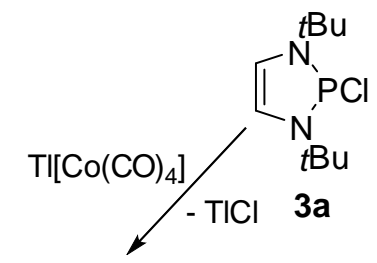

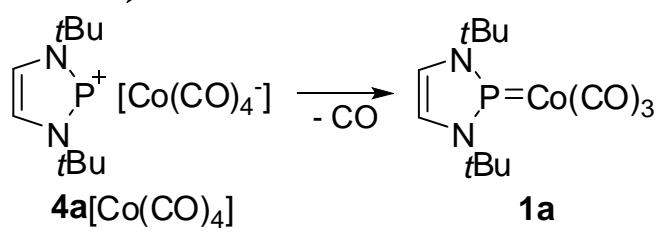

Scheme 3. Reaction of N-heterocyclic chlorophosphane 3a with $\mathrm{TI}\left[\mathrm{Co}(\mathrm{CO})_{4}\right]$ (according to ref. [4]).

In order to verify our hypothesis, we carried out a DFT study to model the decarbonylation of the ionic phosphenium carbonyl metalates $\mathbf{4 a}\left[\mathrm{Mn}(\mathrm{CO})_{5}\right]$ and $\mathbf{4} \mathbf{b}^{\prime}\left[\mathrm{Mn}(\mathrm{CO})_{5}\right]$ to yield the molecular complexes $\mathbf{2} \mathbf{a}$ and $\mathbf{2} \mathbf{b}$ ', respectively. All calculations were carried out at the RI-PBE-D3BJ/def2-tzvp level, and the conductor-like screening model[10] (COSMO) with the solvent parameters for THF was used to simulate solvation effects. The minimum energy reaction paths (Figure 2) suggest that the decarbonylation of $\mathbf{4} \mathbf{b}^{\prime}\left[\mathrm{Mn}(\mathrm{CO})_{5}\right]$ is exergonic after passing a moderately high activation barrier, while the corresponding reaction of $4 \mathrm{a}\left[\mathrm{Mn}(\mathrm{CO})_{5}\right]$ is endergonic and requires nearly twice as much activation energy. The variation in the calculated free energies is mainly due to differences in the energy contributions, the origin of which is clearly reflected in the structural differences of the starting materials, products, and transition states of both reactions (see Figure 2).

The energy optimized structure of $4 \mathrm{a}\left[\mathrm{Mn}(\mathrm{CO})_{5}\right]$ is readily described as an ion pair consisting of essentially undistorted $\mathrm{NHP}$ cations and carbonyl metalate anions at a Mn-P distance of $3.57 \AA$ that indicates the absence of any specific bonding interaction. In contrast, the metal atom in $\mathbf{4} \mathbf{b}^{\prime}\left[\mathrm{Mn}(\mathrm{CO})_{5}\right]$ engages in a much closer contact ( $2.89 \AA$ ) to the phosphorus atom of the cation fragment, and the widening of an equatorial angle in the regular tbp-geometry of the isolated anion in response to the approach of the phosphorus atom results in a coordination geometry best described as distorted octahedral. The Mn-P distance is in this case intermediate between the sums of covalent $\left(2.46 \AA^{[11]}\right)$ and van-der-Waals radii $\left(4.3 \AA^{[12]}\right)$ and suggestive of the presence of some direct $\mathrm{Mn}-\mathrm{P}$ bonding interaction. A similar structure as computed for $\mathbf{4} \mathbf{b}^{\prime}\left[\mathrm{Mn}(\mathrm{CO})_{5}\right]$ had previously been observed for an As-analogue of $4 \mathrm{a}\left[\mathrm{Co}(\mathrm{CO})_{4}\right]$ and was interpreted as a complex supported by an "inverse dative bond" between a Lewis-basic metal atom and a
Lewis-acidic ligand. ${ }^{[4]}$ We attribute the shorter $\mathrm{Mn}-\mathrm{P}$ contact in $\mathbf{4} \mathbf{b}^{\prime}\left[\mathrm{Mn}(\mathrm{CO})_{5}\right]$ compared to $\mathbf{4 a}\left[\mathrm{Mn}(\mathrm{CO})_{5}\right]$ to the lower steric demand of the pan-shaped $\mathrm{N}$-xylyl substituents in the former, which can give way by exposing their flat side to the metal anion fragment. This closing-up of the phosphorus and metal center may also be considered to facilitate the subsequent bond formation step under concomitant $\mathrm{CO}$ cleavage and is thus regarded as the main cause for the lower transition state energy in the reaction of the $\mathrm{N}$-xylyl derivative.
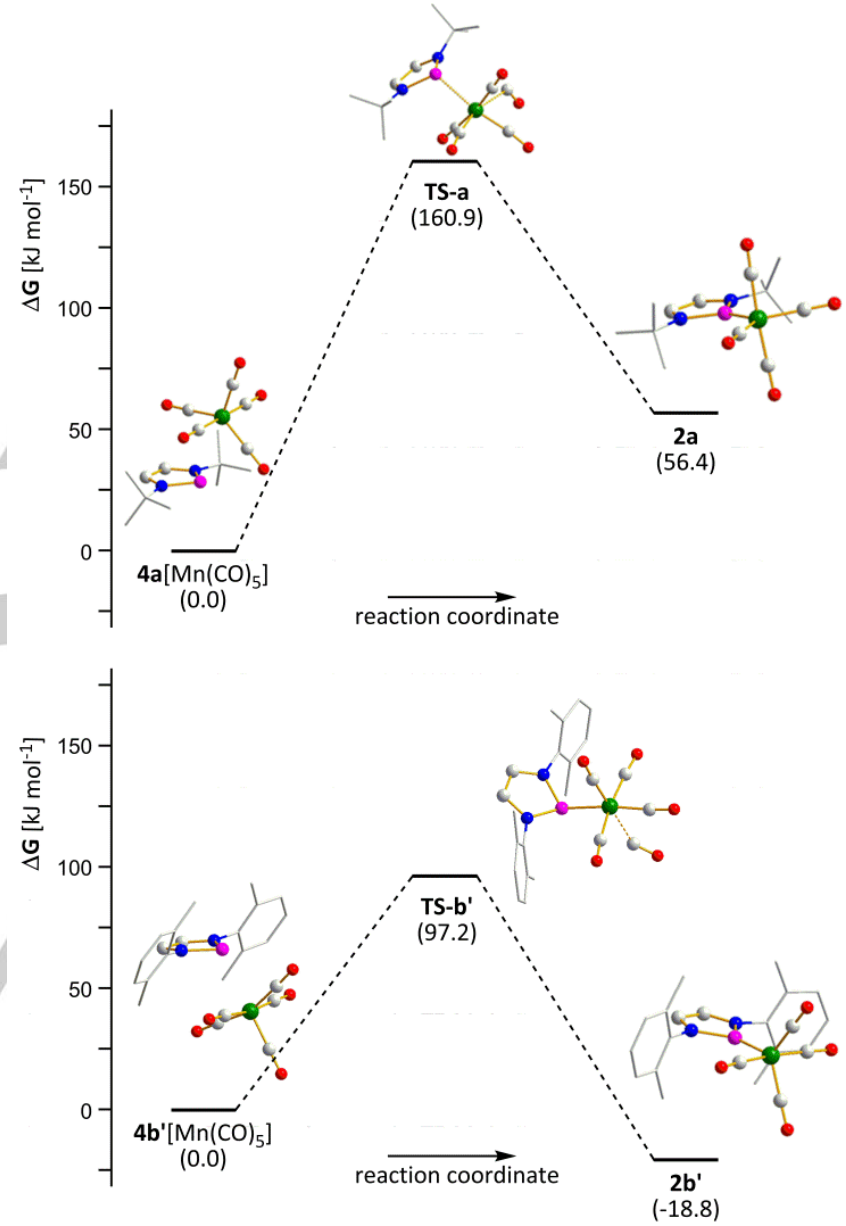

Figure 2. Minimum energy paths with energy optimized molecular structures at the stationary points for the decarbonylation of $4 \mathrm{a}\left[\mathrm{Mn}(\mathrm{CO})_{5}\right]$ (top) and $\mathbf{4 b}$ ' $\left[\mathrm{Mn}(\mathrm{CO})_{5}\right]$ (bottom) calculated at the COSMO-RS/RI-PBE-D3BJ/def2-tzvp level using solvent parameters for THF. Hydrogen atoms in the structure representations are omitted for clarity. Numbers in brackets denote calculated relative free energies in $\mathrm{kJ} \mathrm{mol}^{-1}$.

The energy optimized structures of the neutral complexes $\mathbf{2 a}$ and $\mathbf{2} \mathbf{b}$ ' exhibit quite similar overall shapes, and the geometry of $\mathbf{2} \mathbf{b}$ ' is further a close match to the observed one of $\mathbf{2} \mathbf{b}$ (apart from the different tilt between the NHP ring plane and the $\mathrm{Mn}(\mathrm{CO})_{4}$ unit which had already been addressed, vide supra). The increased steric bulk of the spherical $\mathrm{N}$-tBu substituents induces in $\mathbf{2 a}$ a slight lengthening of the Mn-P distance $(2.106 \AA$ 
vs. $2.070 \AA$ in $\mathbf{2} \mathbf{b}^{\prime}$ ) and a rotation of the NHP ligand which is now aligned parallel rather than orthogonal to the equatorial plane of the metal coordination polyhedron. This feature may be seen as a first qualitative indication of growing steric strain which is further confirmed by the reduced interaction energy between the NHP and metal carbonylate fragments in $2 \mathbf{a}\left(E_{\text {int }}=-289.6 \mathrm{~kJ}\right.$ $\mathrm{mol}^{-1}$ ) compared to $\mathbf{2} \mathbf{b}^{\prime}$ ( $\left.E_{\text {int }}=-351.6 \mathrm{~kJ} \mathrm{~mol}^{-1}\right)$ obtained from an energy decomposition analysis ${ }^{[13]}$ (EDA). The breakdown of the interaction energy into individual bonding contributions reveals that variations in the electrostatic, exchange and orbital terms between both species largely cancel out, and that the lower overall interaction energy for $2 \mathrm{a}\left(\Delta E_{\mathrm{int}}=62 \mathrm{~kJ} \mathrm{~mol}^{-1}\right)$ arises essentially from the larger repulsive term $\left(\Delta E_{\text {rep }}=76 \mathrm{~kJ} \mathrm{~mol}^{-1}\right)$. The higher steric demand of an $\mathrm{N}$-tBu compared to an $\mathrm{N}$-xylyl substituted NHP ligand is, like in the NHC series, ${ }^{\left[{ }^{[0]}\right.}$ reflected in the increased buried volume ${ }^{[14]}$ calculated for the NHP ligands in $\mathbf{2 a}\left(\% V_{\text {bur }}=32.7\right)$ and $\mathbf{2} \mathbf{b}^{\prime}\left(\% V_{\text {bur }}=28.9\right)$, respectively.

The results of the computational studies disclose that the connection between steric bulk and metal binding strength established for $\mathrm{NHC}$ ligands ${ }^{[9]}$ seems in principle also applicable to the isoelectronic NHP ligands. It should be noted that N-Mes or N-Dipp substituents in an NHP fragment can be considered to exert a similar degree of steric encumbrance in the vicinity of the phosphorus atom as $\mathrm{N}$-xylyl substituents so that the results obtained for 2 $2 \mathbf{b}$ ' should also enable a qualitative assessment of structurally related NHP cations like $\mathbf{4 b}$ or $\mathbf{4 c}$, respectively. Similar steric constraints as for $\mathbf{4 a}$ can also be expected for $\mathrm{N}$ tBu-substituted diazaphospholidine derivatives featuring a saturated $\mathrm{CH}_{2} \mathrm{CH}_{2}$ backbone ${ }^{[9]}$ instead of the endocyclic double bond.

The case of the cobalt complexes $\mathbf{1 a}, \mathbf{b}$ is consistent with these considerations if one assumes that the increased bulk of the $\mathrm{N}$ tBu substituents is offset by the smaller steric demand of a $\mathrm{Co}(\mathrm{CO})_{3}$ compared to a $\mathrm{Mn}(\mathrm{CO})_{4}$ fragment so that repulsive interactions cannot compromise the formation of $\mathbf{1 a}$. The comparison of the structures of $\mathbf{1} \mathbf{a}, \mathbf{b}$ with those of $\mathrm{NHC}$ complexes $(\mathrm{NHC}) \mathrm{Ni}(\mathrm{CO})_{\mathrm{n}}(\mathrm{NHC}=\mathrm{IMes}, \mathrm{It} \mathrm{Bu})$ casts some further light on the NHC/NHP analogy. Thus, the sterically less demanding Mes-substituted $\mathrm{N}$-heterocyclic ligands $\mathbf{4 b}$ and IMes form isosteric metal tricarbonyl complexes of composition (IMes) $\mathrm{Ni}(\mathrm{CO})_{3}$ and $(\mathbf{4 b}) \mathrm{Co}(\mathrm{CO})_{3}$, respectively, whereas the isosteric NHC-nickel analogue $(4 a) \mathrm{Co}(\mathrm{CO})_{3}$ is unknown and the carbene reacts with $\mathrm{Ni}(\mathrm{CO})_{4}$ to afford instead a coordinatively unsaturated complex $(\mathrm{ItBu}) \mathrm{Ni}(\mathrm{CO})_{2} \cdot{ }^{[15]}$ This deviation is readily accounted for if one considers that the larger atomic radius of the donor atom of an NHP ligand eases the steric congestion so that accommodation of a sterically more demanding metal tricarbonyl ligand is still feasible. Nonetheless, we assume that similar restrictions as observed in the futile synthesis of $2 \mathbf{a}$ are expected for prospective attempts to prepare cationic complexes of phosphenium ion $\mathbf{4 a}$ with neutral metal fragments like $\mathrm{Fe}(\mathrm{CO})_{4}$ or $\mathrm{Cr}(\mathrm{CO})_{5}$, respectively.

\section{Conclusions}

The different outcome of the reactions of $\mathrm{N}$-Mes and $\mathrm{N}$-tBu substituted $\mathrm{N}$-heterocyclic phosphorus electrophiles with $\mathrm{Na}\left[\mathrm{Mn}(\mathrm{CO})_{5}\right]$ reveals that the accessibility of the targeted $\mathrm{N}$ heterocyclic phosphenium complexes is subject to subtle substituent influences. DFT studies suggest that repulsive steric interactions between the phosphenium ligand and the metal fragment, which depend strongly on the size and shape of the $\mathrm{N}$ substituents in the NHP ligand, play a decisive role. The impact of steric factors on the complex formation reveals close parallels to the chemistry of $\mathrm{NHC}$ complexes, although the effect of steric congestion seems to be eased in a quantitative sense as a consequence of the increased size of the donor atom.

\section{Experimental Section}

All manipulations were carried out in an atmosphere of dry argon or nitrogen using standard vacuum line techniques. Solvents were dried prior to use by common procedures. NMR spectra were recorded on Bruker Avance $400\left({ }^{1} \mathrm{H} 400.1 \mathrm{MHz},{ }^{31} \mathrm{P} 161.9 \mathrm{MHz},{ }^{13} \mathrm{C} 100.6 \mathrm{MHz}\right)$ or Avance $250\left({ }^{1} \mathrm{H} \quad 250.1 \mathrm{MHz},{ }^{31} \mathrm{P} \quad 101.2 \mathrm{MHz},{ }^{13} \mathrm{C} \quad 62.8 \mathrm{MHz}\right)$ spectrometers at $303 \mathrm{~K}$. Chemical shifts were referenced to ext. TMS $\left({ }^{1} \mathrm{H}\right.$, $\left.{ }^{13} \mathrm{C}\right)$ or $85 \% \mathrm{H}_{3} \mathrm{PO}_{4}\left(\equiv=40.480747 \mathrm{MHz},{ }^{31} \mathrm{P}\right)$. FT-IR spectra were recorded on a Thermo Scientific Nicolet iS5 spectrometer equipped with an iD5 ATR unit. Elemental analyses were determined with an Elementar Micro Cube elemental analyzer. $\mathrm{Na}\left[\mathrm{Mn}(\mathrm{CO})_{5}\right]$ and the $\mathrm{NHP}$ derivatives $\mathbf{3 b}$ and $4 \mathrm{a}[\mathrm{OTf}]$ were prepared as described elsewhere. ${ }^{[16][17]}$

Synthesis of $\mathbf{2 b}$ : Bromo-diazaphospholene $\mathbf{3 b}(202 \mathrm{mg}, 0.5 \mathrm{mmol})$ was dissolved in THF $(10 \mathrm{ml})$ and added to a cooled $\left(-78^{\circ} \mathrm{C}\right)$ solution of $\mathrm{Na}\left[\mathrm{Mn}(\mathrm{CO})_{5}\right]$ (109 mg, $\left.0.5 \mathrm{mmol}\right)$ in THF $(10 \mathrm{ml})$. The solution was allowed to warm to room temperature and stirred for $12 \mathrm{~h}$. Volatiles were removed under reduced pressure, the orange residue taken up in $\mathrm{CH}_{2} \mathrm{Cl}_{2}$ $(20 \mathrm{ml})$ and filtered through Celite. The filtrate was evaporated to dryness and the remaining solid washed with pentane $(4 \times 10 \mathrm{ml})$. After drying under vacuum, 2b (143 mg, $58 \%$ ) was obtained as an orange solid. Single crystals suitable for a single-crystal XRD study were obtained by recrystallization from $\mathrm{CH}_{2} \mathrm{Cl}_{2} / \mathrm{Et}_{2} \mathrm{O}$ at $-20^{\circ} \mathrm{C}$. ${ }^{1} \mathrm{H} \mathrm{NMR}\left(\mathrm{CDCl}_{3}\right): \delta=7.00$ (s, $4 \mathrm{H}, \mathrm{C}_{6} \mathrm{H}_{2}$ ), 6.58 (s, $2 \mathrm{H}, \mathrm{NCH}$ ), 2.30 (s, $\left.6 \mathrm{H}, p-\mathrm{CH}_{3}\right), 2.20$ (s, $12 \mathrm{H}, 0$ $\left.\mathrm{CH}_{3}\right)$ ppm. ${ }^{31} \mathrm{P}\left\{{ }^{1} \mathrm{H}\right\}$ NMR $\left(\mathrm{CDCl}_{3}\right): \delta=239.6$ (s) ppm. ${ }^{13} \mathrm{C}\left\{{ }^{1} \mathrm{H}\right\}$ NMR $\left(\mathrm{CDCl}_{3}\right): \delta=226(\mathrm{br}, \mathrm{CO}), 139.8\left(\mathrm{~d},{ }^{5} \mathrm{JPC}_{\mathrm{PC}}=1.1 \mathrm{~Hz}, \mathrm{p}-\mathrm{C}\right), 136.9$ (d, $\left.{ }^{3} \mathrm{JPC}=2.7 \mathrm{~Hz}, o-\mathrm{C}\right), 133.5\left(\mathrm{~d},{ }^{2} \mathrm{JPC}=6.7 \mathrm{~Hz}\right.$, ipso-C), 129.9 (s, m-C), 123.9 (s, NCH) ppm. IR (solid): $\tilde{v}=2019,1950,1930,1903 \mathrm{~cm}^{-1}$ (vCO). IR (THF): $\tilde{v}=2025,1948,1917 \mathrm{~cm}^{-1}$ (vCO). $\mathrm{C}_{24} \mathrm{H}_{24} \mathrm{MnN}_{2} \mathrm{O}_{4} \mathrm{P}$ (490.38): calcd. C 58.78 H 4.93 N 5.71, found C 58.91 H 5.20 N 5.70.

Synthesis of $4 \mathrm{a}\left[\mathrm{Mn}(\mathrm{CO})_{5}\right]$ : Diazaphospholenium triflate $4 \mathrm{a}[\mathrm{OTf}]$ (150 mg, $0.43 \mathrm{mmol})$ was dissolved in THF $(10 \mathrm{ml})$ and added to a cooled $\left(-78^{\circ} \mathrm{C}\right)$ solution of $\mathrm{Na}\left[\mathrm{Mn}(\mathrm{CO})_{5}\right](95 \mathrm{mg}, 0.43 \mathrm{mmol})$ in THF $(10 \mathrm{ml})$. The solution was allowed to warm to room temperature and stirred for $12 \mathrm{~h}$. Volatiles were removed under reduced pressure, the red-orange residue taken up in toluene $(15 \mathrm{ml})$ and filtered through Celite. The filtrate was evaporated to dryness and the remaining solid washed with pentane $(4 \times 15 \mathrm{ml})$. After drying in vacuum $4 \mathrm{a}\left[\mathrm{Mn}(\mathrm{CO})_{5}\right](65 \mathrm{mg}, 38 \%)$ were obtained as a dark red solid. ${ }^{1} \mathrm{H}$ NMR (THF-d 8 ): $\delta=8.40(\mathrm{~s}, 2 \mathrm{H}, \mathrm{NCH}), 1.85$ (d, $18 \mathrm{H}$, $\mathrm{CH}_{3}$ ) ppm. ${ }^{31} \mathrm{P}\left\{{ }^{1} \mathrm{H}\right\}$ NMR (THF-d 8$): \delta=201.5$ (s) ppm. ${ }^{13} \mathrm{C}\left\{{ }^{1} \mathrm{H}\right\}$ NMR (THF$\left.\mathrm{d}_{8}\right): \delta=239.9(\mathrm{br}, \mathrm{CO}), 133.4(\mathrm{~s}, \mathrm{NCH}), 63.5\left(\mathrm{~s}, \mathrm{NCCH}_{3}\right), 31.7\left(\mathrm{~d},{ }^{3} J_{\mathrm{PC}}=\right.$ $8.9 \mathrm{~Hz}, \mathrm{NCCH}_{3}$ ) ppm. IR (solid): $\tilde{v}=2011,1896,1846 \mathrm{~cm}^{-1}(v \mathrm{CO})$.

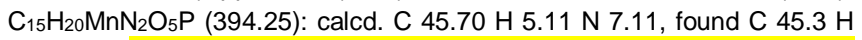
$6.1 \mathrm{~N}$ 7.3. The deviation of the analytical composition from the calculated values is attributable to the presence of minor impurities (inorganic salts, residual solvents). 
Computational studies: RI-DFT calculations were carried out on the bwForCluster Justus with the TURBOMOLE [18] program suite (version 7.2.2017 [19]). Energy optimization of molecular structures and calculation of harmonic frequencies were carried out using the PBE functional with a def2-tzvp basis set, ${ }^{[20]}$ Grimme's D3BJ formalism ${ }^{[21]}$ to include dispersion effects, and the conductor-like screening model (COSMO) [10] with the solvent parameters for THF to simulate solvation effects. The stationary points located were identified as local minima or transition states on the energy hypersurface, respectively, by harmonic vibrational frequency calculations. Energy decomposition analysis was performed according to the scheme described by $\mathrm{Su}$ and $\mathrm{Li}^{[13]}$ using the tools implemented in the software. The buried volume of phosphenium ligands was calculated using the SambVca 2.0 online tool ${ }^{[22]}$ with the default settings provided.

Crystallography: Single X-ray diffraction data of $\mathbf{2 b}$ were measured with a Nonius Kappa CCD diffractometer using Mo- $K_{\alpha}$ radiation $(\Lambda=0.71073$ $\AA$ ). A crystal was selected under Formblin $Y$ perfluoro-oil, mounted on a nylon loop, and immediately placed in a cold stream of $\mathrm{N}_{2}$. The structure was solved by direct methods (SHELXS-2014 ${ }^{[23]}$ ) and refined with a fullmatrix least-squares scheme on $F^{2}$ (SHELXL-2014 ${ }^{[23]}$ ). A semi-empirical absorption correction from equivalents was applied. Non-hydrogen atoms were refined anisotropically and hydrogen atoms with a riding model. Further crystallographic data and details on the structure solution are given in the Supporting Information. CCDC-1839223 contains the supplementary crystallographic data for $\mathbf{2 b}$. These data can be obtained free of charge from the Cambridge Crystallographic Data Centre via www.ccdc.cam.ac.uk/data_request/ cif.

\section{Acknowledgements}

The computational studies were supported by the bwHPC initiative and the bwHPC-C5 project provided through the associated compute services of the JUSTUS HPC facility at the University of Ulm. bwHPC and bwHPC-C5 (http://www.bwhpcc5.de) are funded by the state of Baden-Württemberg and the DFG (grant no. INST 40/467-1 FUGG). We further thank B. Förtsch for elemental analyses and Dr. W. Frey (Institute of Organic Chemistry, University of Stuttgart) for the collection of X-ray data sets.

Keywords: $\mathrm{P}$ ligands $\cdot \mathrm{N}$-heterocyclic phosphenium complexes - ligand design $\bullet$ steric effects $\cdot$ reaction mechanisms
[1] a) R. T. Paine, R. W. Light, J. Am. Chem. Soc. 1978, 100, 2230-2231; b) L. D. Hutchins, R. T. Paine, C. F. Campana, J. Am. Chem. Soc. 1980, 102, 4521-4523.

[2] Reviews: a) A. H. Cowley, R. A. Kemp, Chem. Rev. 1985, 85, 367-382; b) L. Rosenberg, Coord.Chem. Rev. 2012, 256, 606-626; c) D. Gudat in Comprehensive Inorg. Chem. II, Vol 1 (Eds.: J. Reedijk, K. Poeppelmeier), Elsevier, Oxford, 2013, pp. 587-621.

[3] H. Lang, M. Leise, C. Emmerich, J. Organomet. Chem. 1991, 418, C9C13.

[4] S. Burck, J. Daniels, T. Gans-Eichler, D. Gudat, K. Nättinen, M. Nieger, Z. Anorg. Allg. Chem. 2005, 631, 1403-1412.

[5] H. U. Reisacher, E. N. Duesler, R. T. Paine, J. Organomet. Chem., 1998, 564, 13-20.

[6] M. Gediga, C. M. Feil, S. H. Schlindwein, J. Bender, M. Nieger, D. Gudat, Chem. Eur. J., 2017, 23, 11560-11569.

[7] M. Gediga, S. H. Schlindwein, J. Bender, M. Nieger, D. Gudat, Angew. Chem. Int. Ed., 2017, 56, 15718-15722.

[8] S. Burck, D. Gudat, Inorg. Chem., 2008, 47, 315-321.

[9] Reviews: a) L. Cavallo, A. Correa, C. Costabile, H. Jacobsen, J. Organomet. Chem. 2005, 690, 5407-5413; b) S. Díez-González, S. P. Nolan, Coord. Chem. Rev. 2007, 251, 874-883; c) T. Dröge, F. Glorius, Angew. Chem. Int. Ed. 2010, 49, 6940-6952.

[10] A. Klamt and G. Schüürmann, J. Chem. Soc. Perkin Trans. 2, 1993, 799-805.

[11] B. Cordero, V. Gómez, A. E. Platero-Prats, M. Revés, J. Echeverría, E. Cremades, F. Barragán, S. Alvarez, Dalton Trans. 2008, 2832-2838.

[12] S. Alvarez, Dalton Trans. 2013, 42, 8617- 8636.

[13] P. Su, H. Li, J. Chem. Phys. 2009, 131, 014102(1-15).

[14] A. Poater, F. Ragone, S. Giudice, C. Costabile, R. Dorta, S. P. Nolan, L. Cavallo, Organometallics 2008, 27, 2679-2681.

[15] R. Dorta, E. D. Stevens, N. M. Scott, C. Costabile, L. Cavallo, C. D. Hoff, S. P. Nolan, J. Am. Chem. Soc. 2005, 127, 2485-2495.

[16] J. W. Dube, G. J. Farrar, E. L. Norton, K. L. S. Szekely, B. F. T. Cooper, C. I. B. Macdonald, Organometallics, 2009, 28, 4377-4384.

[17] S. Burck, D. Gudat, M. Nieger, W. W. du Mont, J. Am. Chem. Soc. 2006, 128, 3946-3955

[18] R. Ahlrichs, M. Bär, M. Häser, H. Horn, C. Kölmel, Chem. Phys. Lett. 1989, 162, 165-169.

[19] TURBOMOLE V7.2 2017, a development of University of Karlsruhe and Forschungszentrum Karlsruhe $\mathrm{GmbH}$, 1989-2007, TURBOMOLE $\mathrm{GmbH}$, since 2007; available from http://www.turbomole.com.

[20] F. Weigend, R. Ahlrichs, Phys. Chem. Chem. Phys. 2005, 7, 3297-3305.

[21] S. Grimme, S. Ehrlich, L. Goerigk, J. Comp. Chem. 2011, 32, 14561465.

[22] A. Poater, B. Cosenza, A. Correa, S. Giudice, F. Ragone, V. Scarano, L. Cavallo, Eur. J. Inor. Chem. 2009, 1759-1766.

[23] G. M. Sheldrick, Acta Crystallogr. Sect. A 2008, 64, 112-122.

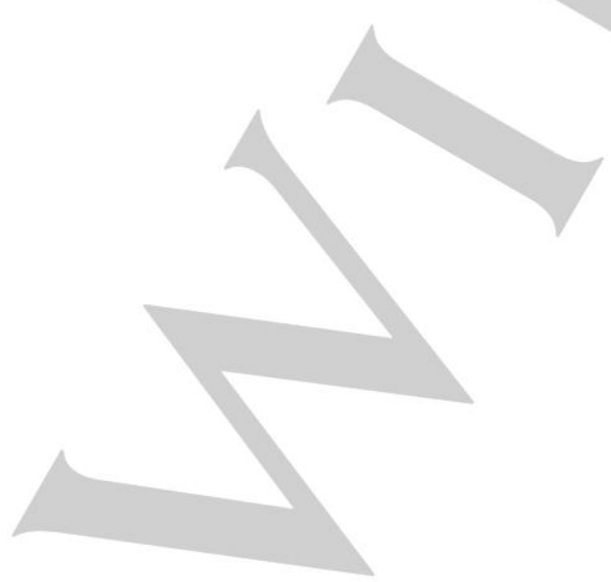


Entry for the Table of Contents (Please choose one layout)

\section{FULL PAPER}

Reactions of $\mathrm{Na}\left[\mathrm{Mn}(\mathrm{CO})_{5}\right]$ with two different $\mathrm{N}$-heterocyclic phosphines yield either an ionic phosphenium metalate or a covalent phosphenium complex. DFT studies allow relating the different outcome to the steric properties of the P-ligands.

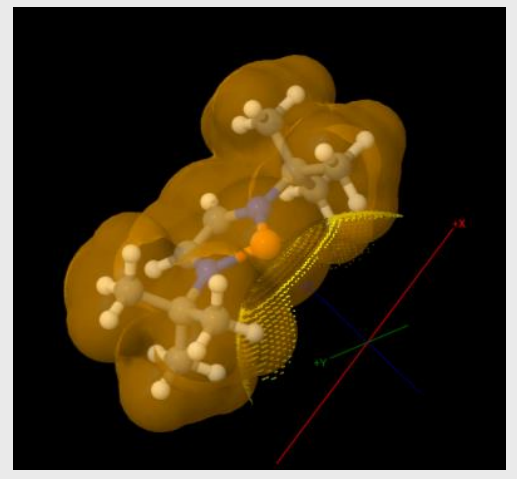

M. Papendick, C. M. Feil, M. Nieger, D. Gudat*

Page No. - Page No.

Steric control in reactions of $\mathrm{N}$ heterocyclic phosphorus electrophiles with pentacarbonyl manganate(-I) 
Additional Author information for the electronic version of the article.

Author:

Author:

ORCID identifier

Author:

ORCID identifier 